\title{
Specify New Tumor Metastasis Site
}

National Cancer Institute

\section{Source}

National Cancer Institute. Specify New Tumor Metastasis Site. NCI Thesaurus. Code C159722.

A directive to specify the new tumor metastasis site. 